\title{
Article \\ Biodirected Synthesis of Silver Nanoparticles Using Aqueous Honey Solutions and Evaluation of Their Antifungal Activity against Pathogenic Candida Spp.
}

\author{
Grzegorz Czernel ${ }^{1, *}{ }^{\mathbb{D}}$, Dominika Bloch ${ }^{2}$, Arkadiusz Matwijczuk ${ }^{1}{ }^{\mathbb{D}}$, Jolanta Cieśla ${ }^{3}$, \\ Monika Kędzierska-Matysek ${ }^{4}$, Mariusz Florek ${ }^{4}{ }^{(1)}$ and Mariusz Gagoś ${ }^{2,5}$
}

\section{check for} updates

Citation: Czernel, G.; Bloch, D.; Matwijczuk, A.; Cieśla, J.; Kędzierska-Matysek, M.; Florek, M.; Gagoś, M. Biodirected Synthesis of Silver Nanoparticles Using Aqueous Honey Solutions and Evaluation of Their Antifungal Activity against Pathogenic Candida Spp. Int. J. Mol. Sci. 2021, 22, 7715. https://doi.org/ $10.3390 /$ ijms 22147715

Academic Editor: Alina Maria Holban

Received: 4 June 2021

Accepted: 14 July 2021

Published: 19 July 2021

Publisher's Note: MDPI stays neutral with regard to jurisdictional claims in published maps and institutional affiliations.

Copyright: (c) 2021 by the authors. Licensee MDPI, Basel, Switzerland. This article is an open access article distributed under the terms and conditions of the Creative Commons Attribution (CC BY) license (https:// creativecommons.org/licenses/by/ $4.0 /)$.
1 Department of Biophysics, University of Life Sciences in Lublin, Akademicka 13, 20-950 Lublin, Poland; arkadiusz.matwijczuk@up.lublin.pl

2 Department of Cell Biology, Institute of Biology and Biochemistry, Maria Curie-Skłodowska University, Akademicka 19, 20-033 Lublin, Poland; dominika.bloch@poczta.umcs.lublin.pl (D.B.); mariusz.gagos@poczta.umcs.lublin.pl (M.G.)

3 Institute of Agrophysics, Polish Academy of Sciences, Doświadczalna 4, 20-290 Lublin, Poland; j.ciesla@ipan.lublin.pl

4 Department of Quality Assessment and Processing of Animal Products, University of Life Sciences in Lublin, Akademicka 13, 20-950 Lublin, Poland; monika.matysek@up.lublin.pl (M.K.-M.); mariusz.florek@up.lublin.pl (M.F.)

5 Department of Biochemistry and Molecular Biology, Medical University of Lublin, 20-093 Lublin, Poland

* Correspondence: grzegorz.czernel@up.lublin.pl

Abstract: Silver nanoparticles (AgNPs) were synthesized using aqueous honey solutions with a concentration of $2 \%, 10 \%$, and $20 \%$-AgNPs-H2, AgNPs-H10, and AgNPs-H20. The reaction was conducted at $35{ }^{\circ} \mathrm{C}$ and $70{ }^{\circ} \mathrm{C}$. Additionally, nanoparticles obtained with the citrate method (AgNPs-C), while amphotericin B (AmB) and fluconazole were used as controls. The presence and physicochemical properties of AgNPs was affirmed by analyzing the sample with ultraviolet-visible (UV-Vis) and fluorescence spectroscopy, scanning electron microscopy (SEM), and dynamic light scattering (DLS). The 20\% honey solution caused an inhibition of the synthesis of nanoparticles at $35{ }^{\circ} \mathrm{C}$. The antifungal activity of the AgNPs was evaluated using opportunistic human fungal pathogens Candida albicans and Candida parapsilosis. The antifungal effect was determined by the minimum inhibitory concentration (MIC) and disc diffusion assay. The highest activity in the MIC tests was observed in the AgNPs-H2 variant. AgNPs-H10 and AgNPs-H20 showed no activity or even stimulated fungal growth. The results of the Kirby-Bauer disc diffusion susceptibility test for $C$. parapsilosis strains indicated stronger antifungal activity of AgNPs-H than fluconazole. The study demonstrated that the antifungal activity of AgNPs is closely related to the concentration of honey used for the synthesis thereof.

Keywords: silver nanoparticles; honey; aggregation; antifungal activity; zeta potential; molecular spectroscopy

\section{Introduction}

Candidiasis is one of the most common infections in the world. The disease is caused by the Candida albicans and Candida non-albicans groups. C. albicans is the most prevalent yeast species in oral, genital, and skin infections ( $\geq 90 \%)$. It is also responsible for severe systemic mycoses in immunosuppressed patients. Candida parapsilosis is an important factor in catheter-related yeast bloodstream infections. The main factor in C. parapsilosis virulence is its ability to colonize artificial surfaces, which is associated with the ability of this yeast to form biofilms. The species is regarded as an important etiological factor of nosocomial infections in patients undergoing medical procedures that require the use of vascular catheters and tubing [1]. The administration of a wide range of antifungal 
drugs (e.g., amphotericin B and azoles) has been found to increase drug resistance [2]. In this aspect, nanotechnology offers a possibility of development of new therapeutic agents. Due to their unique physicochemical properties, silver nanoparticles (AgNPs) are increasingly being used in science and technology [3]. With its strong antimicrobial properties, nanosilver is applied in medicine in fabrics, coatings, implants, and dressings, as well as in the treatment of wounds and burns [4]. It is also used for disinfection of water and in elements of medical devices and instruments [5]. The controlled synthesis of metal nanoparticles of a defined morphology is important for fields such as biochemistry, catalysis, and medicine [6] Nanomaterials also represent a promising novel class of materials to be used as antimicrobial agents $[7,8]$.

Currently, there are several known methods of AgNP synthesis-physical, chemical, and biological. Green synthesis is the most suitable method in biomedicine for safety reasons [9]. In this method, nanoparticles are synthesized using natural products which themselves often have antimicrobial properties, thereby enhancing the effect of the nanoparticles through synergistic or additive effects. For these reasons and due to ecological concerns, the method of green synthesis is currently gaining in popularity. For the green synthesis of nanoparticles to occur, it is necessary to provide $\mathrm{Ag}^{+}$ions with a biological reducing agent. In most cases, reducing agents also act as stabilizers and coating agents. AgNP synthesis in biological systems takes place in the presence of numerous organic compounds such as carbohydrates, protein, free amino acids, enzymes, phenolic compounds, terpenoids, and alkaloids, with the ability to donate electrons required for reduction of $\mathrm{Ag}^{+}$ions to $\mathrm{Ag}^{0}$. The synthesis of AgNPs can also be triggered with the use of aqueous honey solutions, where the sugars contained therein, mainly mono- and disaccharides, act as the key reducing agents $[10,11]$.

Honey is known as an excellent remedy for healing wounds since ancient times. As reported recently, honey may be suggested as a potential source of natural antimicrobial agents against $C$. albicans, i.e., the most common fungal pathogen in humans [12]. The use of honey for AgNP synthesis offers numerous benefits due to its inherent antimicrobial properties.

Only sparse information is available on the antifungal activity of AgNPs biosynthesized using honey [13-15]. Therefore, in this study, we investigated their activity against two opportunistic pathogenic C. albicans and C. parapsilosis species. Additionally, the impact of the concentration of honey used for the synthesis of nanoparticles on their antifungal activity was analyzed.

\section{Result}

\subsection{Biosynthesis and Spectroscopic Characterization of AgNPs}

The synthesis of nanoparticles with the citrate reduction method is described in Section 5 and in our previous publication [16]. The synthesis of nanoparticles using aqueous honey solutions (AgNPs-H) can be confirmed by measuring the surface plasmon resonance (SPR) band using electronic absorption spectroscopy. The ultraviolet-visible (UV-Vis) spectrum of the reaction mixture has an absorption peak at $400 \mathrm{~nm}$; this evidences the presence of SPR of nanoparticles. A single SPR band indicates that nanoparticles have a spherical shape $[17,18]$. During the first stage of the experiment, the synthesis of AgNPs was conducted at temperature of $35^{\circ} \mathrm{C}$ in aqueous honey solutions at three concentrations: $2 \%, 10 \%$, and $20 \%$ (AgNPs-H2, AgNPs-H10, and AgNPs-H20). The precursor $\left(\mathrm{AgNO}_{3}\right)$ concentration in each sample was $1 \mathrm{mM}, \mathrm{pH}$ 9.5. The reducing sugars glucose and fructose naturally occurring in honey were the reducing factor, and proteins were the capping factor [19]. An alkaline environment is necessary for AgNP synthesis; a high $\mathrm{pH}$ value facilitates the opening of the glucose ring by splitting the $\alpha$-proton from the oxygen ring, and metal ions oxidize glucose to gluconic acid. Initially, the formation of nanoparticles was confirmed by the visible change in the color of the synthesis mixture from pale yellow to light brown. This eventual color change is related to the SPR of nanosilver, which results in the relevant $\mathrm{UV}-\mathrm{Vis}$ spectrum. 
Figure 1A presents the UV-Vis spectra for the aqueous honey solutions with concentrations of $2 \%, 10 \%$, and $20 \%$ at 5 and $15 \mathrm{~min}$ after the addition of $\mathrm{Ag}^{+}$ions at $35^{\circ} \mathrm{C}$. In the $2 \%$ solution, a characteristic SPR band centered at approximately $400 \mathrm{~nm}$ was observed after $5 \mathrm{~min}$. In the $10 \%$ and $20 \%$ solutions, no spectral changes that could indicate the formation of nanostructures were observed.
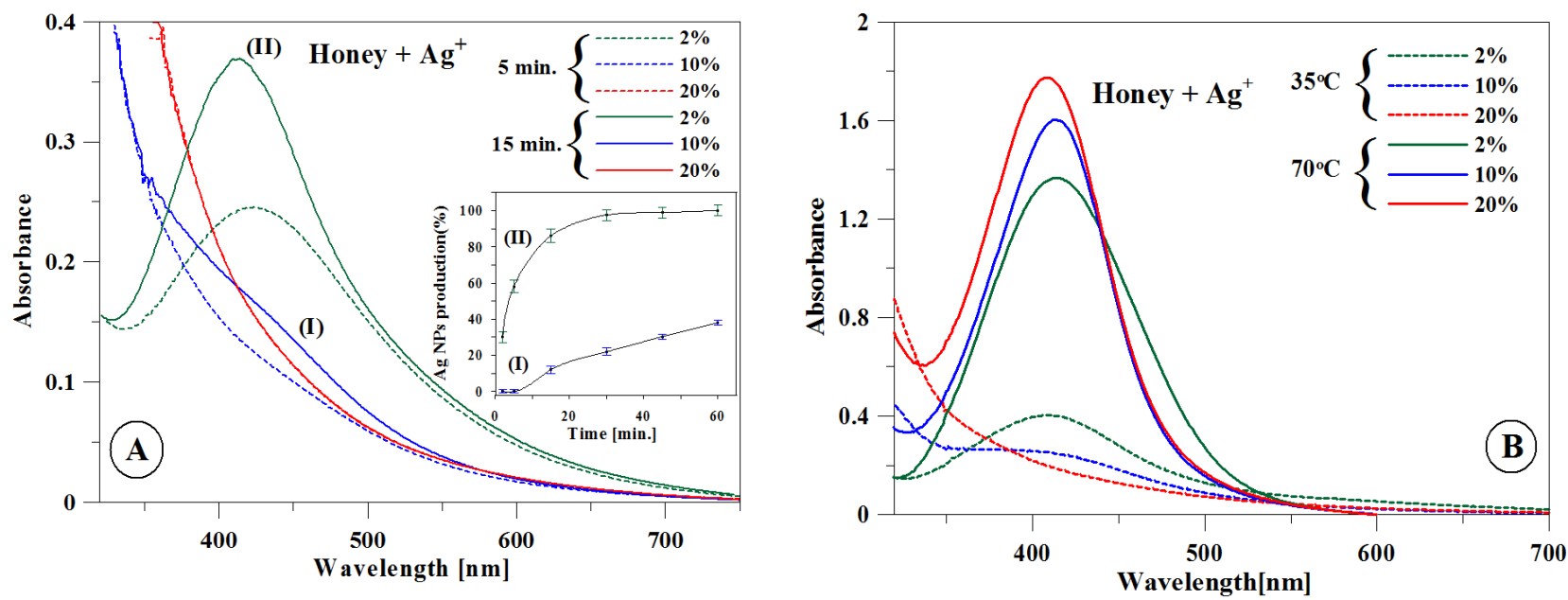

Figure 1. (A) Ultraviolet-visible (UV-Vis) spectra of silver nanoparticles (AgNPs) recorded after 5 (dotted line) and $15 \mathrm{~min}$ (solid line) for the $2 \%, 10 \%$, and $20 \%$ concentrations at $35^{\circ} \mathrm{C}$. Inset: Changing rate of production of AgNPs measured by changes in absorbance at $400 \mathrm{~nm}$ with time. (B) Spectra for the $2 \%, 10 \%$, and $20 \%$ concentrations recorded at $35^{\circ} \mathrm{C}$ (dotted line) and $70^{\circ} \mathrm{C}$ (solid line) after $1 \mathrm{~h}$.

After $15 \mathrm{~min}$, a relatively wide low-intensity band was registered for the $10 \%$ solution. In the case of the $20 \%$ solution, even after $60 \mathrm{~min}$, no spectral changes that would indicate the presence of AgNP synthesis in the relevant combination of concentration and temperature were observed. A change in the rate of AgNP formation relative to the reaction speed is presented in the inset in Figure 1A. Since the maximum SPR is directly proportional to the concentration of AgNPs, the above analysis allows the estimation of the relative synthesis efficiency in the described system. Figure 1B presents the SPR spectra for AgNPs-H2, AgNPs-H10, and AgNPs-H20 at the temperatures of $35^{\circ} \mathrm{C}$ and $70^{\circ} \mathrm{C}$ after $60 \mathrm{~min}$. This was the minimum time frame required for the full synthesis of nanoparticles to take place. In the case of the AgNPs-20 synthesis at the temperature of $70{ }^{\circ} \mathrm{C}$, a band with the highest intensity was recorded. The AgNPs-H2, AgNPs-H10, and AgNPs-H20 produced bands with the maxima at $414 \mathrm{~nm}, 413 \mathrm{~nm}$, and $407 \mathrm{~nm}$, respectively. The full width calculated for the final bands at half-maximum ( $51 \mathrm{~nm}, 40 \mathrm{~nm}$, and $43 \mathrm{~nm}$ for AgNPs-2, AgNPs-10, and AgNPs-20, respectively) indicates that the highest uniformity was observed for AgNPs obtained using the $10 \%$ honey solution [20].

Figure $2 \mathrm{~A}$ presents the resonance light scattering (RLS) spectra for the $2 \%(\mathrm{H}-2)$ and $20 \%(\mathrm{H}-20)$ solutions of pure honey at the temperatures of $35^{\circ} \mathrm{C}, 70{ }^{\circ} \mathrm{C}$, and $70{ }^{\circ} \mathrm{C}$ after increasing the $\mathrm{pH}$ value to 9.5. The initial $\mathrm{pH}$ of the solutions was 5.5. For the H-2 concentration, the increase in the temperature and the change in $\mathrm{pH}$ caused no significant changes in the intensity of the RLS spectrum. For H-20, on the other hand, the intensity of the RLS band increased with the temperature rise to $70^{\circ} \mathrm{C}$ but dropped at the higher $\mathrm{pH}$.

Figure 2B presents the emission spectra for the $\mathrm{H}-2$ and $\mathrm{H}-20$ solutions, as well as the respective electronic absorption spectra (inset A). As shown, the higher absorbance of the H-20 sample is correlated with the lower intensity of emission spectra, particularly with regard to the band under excitation at $280 \mathrm{~nm}$. The effect may be associated with the fluorescence-quenching effect of the concentration or the lower availability of fluorophores (e.g., amino acids, polyphenols) [21,22] in the $\mathrm{H}-20$ sample due to aggregation. 

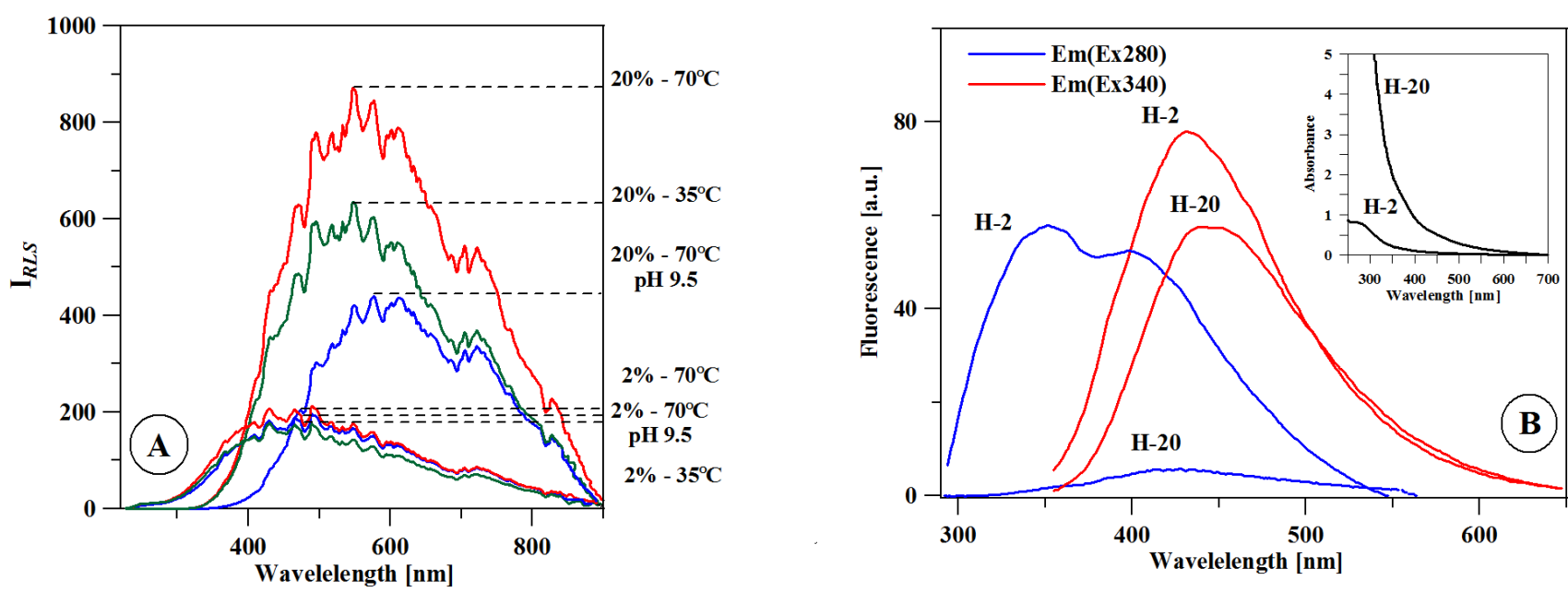

Figure 2. (A) Resonance light scattering (RLS) spectra of pure honey in different temperature, concentration, and $\mathrm{pH}$ conditions. (B) Fluorescence emission spectra of honey at the $2 \%$ and $20 \%$ concentrations. Inset: Electronic absorption spectra for analogical samples.

\subsection{Scanning Electron Microscopy}

Scanning electron microscopy (SEM) was employed to characterize the size, shape, and morphology of AgNPs synthesized at $70{ }^{\circ} \mathrm{C}$. An SEM image of AgNPs is shown in Figure 3. It elucidates the formation of isotropic and nearly spherical nanoparticles, which is in agreement with the shape from the SPR band in the UV-Vis spectra. The images also showed a small number of rod-shaped nanoparticles. These structures can be formed during synthesis, as acquisition of all nanoparticles with a specific shape and size is quite difficult. This is related to the fact that the balance between nucleation and growth is difficult to regulate during the synthesis of nanoparticles in aqueous solutions [17]. The average particle size measured in the images was $42-55 \mathrm{~nm}$ (AgNPs-C), $55-75 \mathrm{~nm}$ (AgNPs-H2), 55-70 nm (AgNPs-H10), and 66-80 nm (AgNPs-H20).

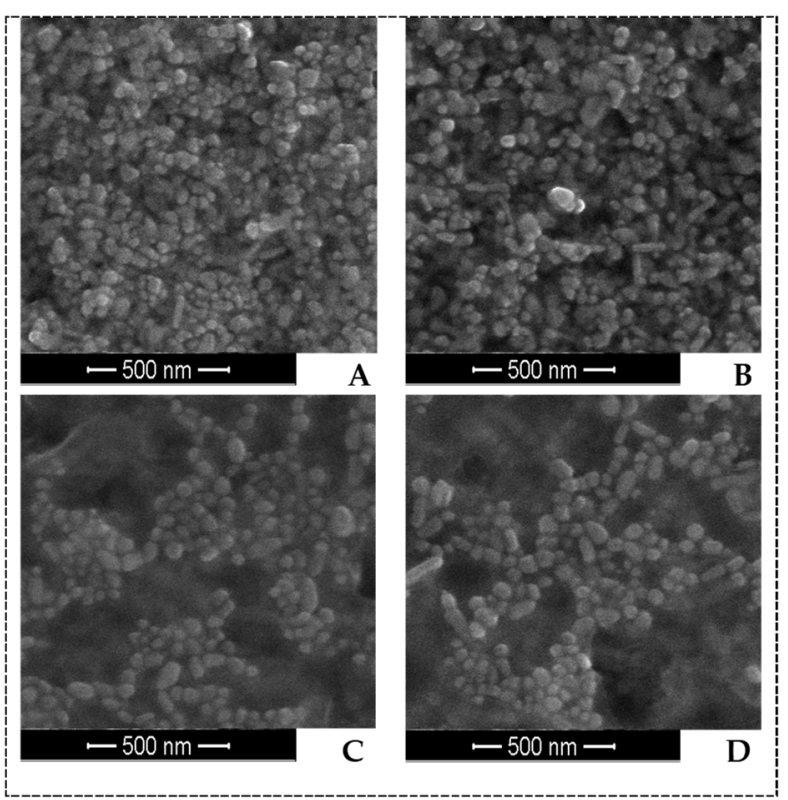

Figure 3. Scanning electron microscopy micrographs of AgNPs (scale $500 \mathrm{~nm}$ ): (A) AgNPs-C, (B) AgNPs-H2, (C) AgNPs-H10, and (D) AgNPs-H20; synthesis at $70{ }^{\circ} \mathrm{C}$. 


\subsection{Dynamic Light Scattering Study}

The results of the particle size measurement (dynamic light scattering method), zeta potential (ZP; laser doppler electrophoresis method) of dispersed particles, and the electrolytic conductivity (EC) of the samples are summarized in Table 1. Moreover, since the samples after the AgNP synthesis still contained some ingredients of the initial dispersing medium used (i.e., citrate or honey solution), the properties of honey solutions at the concentrations of $2 \%, 10 \%$, and $20 \%$ (i.e., $\mathrm{H} 2, \mathrm{H} 10$ and $\mathrm{H} 20$, respectively) and the citrate solution (C) are shown in Table 1.

Table 1. The properties of both the samples after AgNPs synthesis and the initial solutions used.

\begin{tabular}{ccccc}
\hline Sample & Z ave $_{\text {anm }}$ & PdI & EC $(\mathbf{m S} / \mathbf{c m})$ & ZP $(\mathbf{m V})$ \\
\hline AgNPs-C & $18 \pm 1$ & $0.65 \pm 0.04$ & $0.082 \pm 0.002$ & $-43 \pm 1$ \\
C & - & - & $0.276 \pm 0.003$ & - \\
\hline AgNPs-H2 & $63 \pm 6$ & $0.76 \pm 0.12$ & $0.069 \pm 0.001$ & $-27 \pm 3$ \\
H2 & $382 \pm 26$ & $0.46 \pm 0.05$ & $0.032 \pm 0.003$ & $-28 \pm 3$ \\
\hline AgNPs-H10 & $86 \pm 27$ & $0.76 \pm 0.18$ & $0.120 \pm 0.001$ & $-31 \pm 1$ \\
H10 & $400 \pm 19$ & $0.40 \pm 0.06$ & $0.152 \pm 0.001$ & $-25 \pm 1$ \\
\hline AgNPs-H20 & $106 \pm 2$ & $0.96 \pm 0.04$ & $0.200 \pm 0.001$ & $-28 \pm 2$ \\
H20 & $405 \pm 12$ & $0.36 \pm 0.03$ & $0.252 \pm 0.002$ & $-23 \pm 1$ \\
\hline
\end{tabular}

$Z_{\text {ave }}$ - the intensity weighted mean hydrodynamic diameter; PdI-polydispersity index; EC-electrolytic conductivity; $\mathrm{ZP}$ —zeta potential; the results are shown as the mean value from 6 independent measurements \pm standard deviation.

In the case of the citrate solution, the intensity of scattered light was too low to obtain reliable results. In the systems based on the honey solutions, $Z_{\text {ave }}$ decreased and PdI increased after the AgNP synthesis, confirming the presence of small particles next to the large ones. The values of PdI higher than 0.5 pointed out non-homogeneity of the samples in terms of the size of dispersed particles (reflected as a non-monomodal particle size distribution, i.e., the dependence of the percentage of scattered light intensity on the particle diameter). In this case, the analysis of the peak location would be more suitable for characterization of the sample than the use of the $Z_{\text {ave }}$ value. For all the honey concentrations used, the AgNP synthesis resulted in the appearance of a new peak with the maximum at about $30 \mathrm{~nm}$ next to the peak determined for the honey solutions (at the hydrodynamic diameter higher than $100 \mathrm{~nm}$ ). It should be stressed that the ingredients of the aqueous solution of honey may form assemblies whose size decreases with dilution [23]. For better determination of differences between the samples after and before the AgNP synthesis, differential particle size distributions were obtained, considering only the effects which led to an increase in the percentage of scattered light intensity [24]. Accordingly, it was observed that the AgNP synthesis resulted in an increase in the peak height at a particle size of 24 and $142 \mathrm{~nm}$ for AgNPs-H2, 24 and $164 \mathrm{~nm}$ for AgNPs-H10, and 28 and $220 \mathrm{~nm}$ for AgNPs-H20.

The zeta potential distributions were monomodal for all samples studied. The AgNP synthesis did not generate new peaks. Compared to the honey solutions, an increase in the percentage of scattered light intensity was observed at $-16 \mathrm{mV}$ for AgNPs-H2 and $-30 \mathrm{mV}$ for both AgNPs-H10 and AgNPs-H20.

\subsection{Determination of Minimal Inhibitory Concentration}

Due to the low efficiency of the synthesis carried out at $35^{\circ} \mathrm{C}$, nanoparticles obtained at a temperature of $70{ }^{\circ} \mathrm{C}$ were used in the analyses of antifungal activity. The antifungal activity of AgNPs-H against two Candida spp. strains was assessed using the broth microdilution method. The activity of AgNPs-H was compared with that of the nanoparticles obtained with the citrate reduction method (AgNPs-C). The minimal inhibitory concentration (MIC) values of four colloidal suspensions of AgNPs against Candida spp. cells are presented in Table 2. Both species were shown to be susceptible to very low concentrations 
of AgNPs-H2 and AgNPs-C. The lowest MIC values were obtained for AgNPs-H2, i.e., $0.5 \mu \mathrm{g} / \mathrm{mL}$, in both strains. The AgNPs-H10 and AgNPs-H20 solutions did not exhibit any antifungal activity in the tested concentration range. The sodium citrate and honey solutions applied in the tested concentration range did not have any antifungal activity against the Candida spp.

Table 2. Minimal inhibitory concentrations (MICs) of silver nanoparticles (AgNPs) against Candida strains.

\begin{tabular}{ccccc}
\hline \multirow{2}{*}{ Fungal Strains } & \multicolumn{2}{c}{ MIC $(\mu \mathrm{g} / \mathrm{mL})$} & & \\
\cline { 2 - 5 } & AgNPs-C & AgNPs-H2 & AgNPs-H10 & AgNPs-H20 \\
\hline C. albicans & 2 & 0.5 & - & - \\
\hline C. parapsilosis & 1 & 0.5 & - & - \\
\hline
\end{tabular}

Figure 4 shows the dependence of the optical density (OD) 600 value of the analyzed suspensions on the concentration of nanoparticles. AgNPs-H20 applied in the concentration range of $16-4 \mu \mathrm{g} / \mathrm{mL}$ and $16-8 \mu \mathrm{g} / \mathrm{mL}$ stimulated the growth of $C$. albicans and $C$. parapsilosis, respectively. The same effect of AgNPs-H10 used in the range of $16-8 \mu \mathrm{g} / \mathrm{mL}$ was observed in the case of $C$. albicans. Pure honey solutions, $\mathrm{H}-20$ and $\mathrm{H}-10$ showed a similar fungal stimulation effect to AgNPs-H20 and AgNPs-H10, respectively.

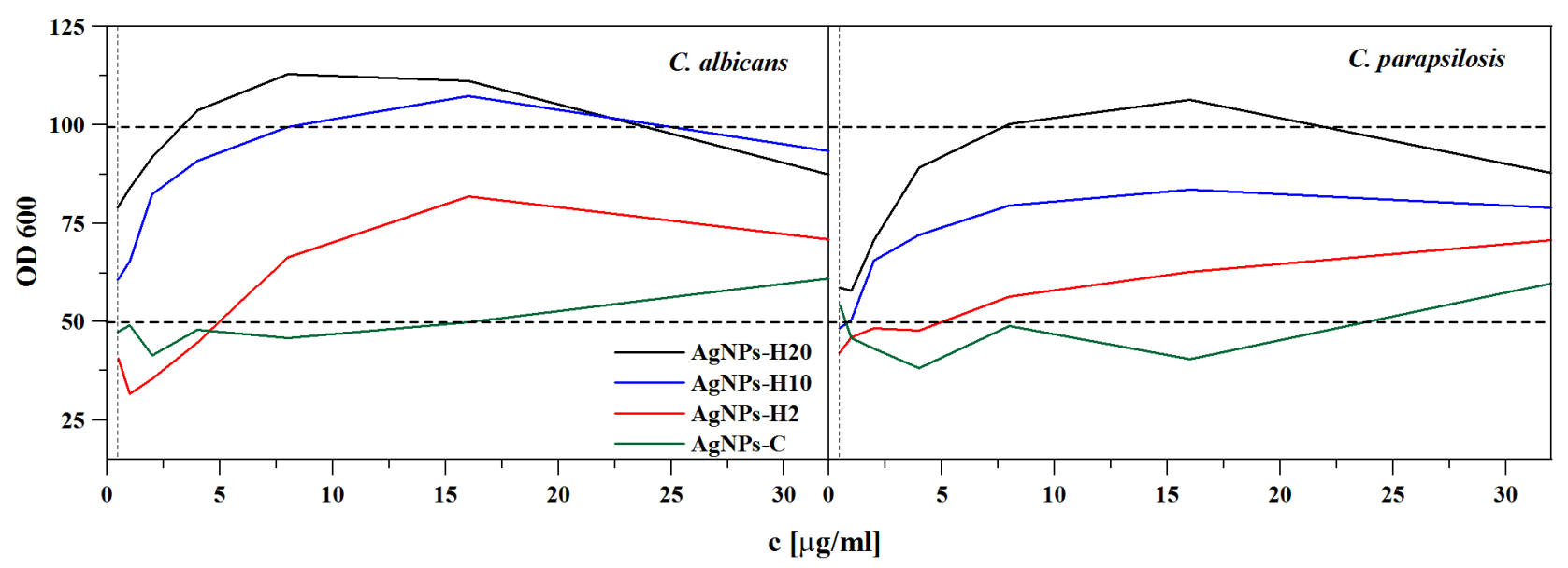

Figure 4. Optical density (OD) at $600 \mathrm{~nm}$ as a function of the silver nanoparticle AgNP concentration.

\subsection{Disc Diffusion Assay}

The results for amphotericin B (AmB), fluconazole, AgNPs-H20, AgNPs-H10, AgNPs2, and AgNPs-C are presented below. The zone of inhibition (ZOI) in millimeters of respective discs loaded with different concentrations of the antifungal agents was determined, and the results are shown in Figure 5. No significant differences were observed between the nanoparticles obtained in the different concentrations of honey in the disc diffusion assay.

The diameters of the inhibition zones of the analyzed AgNP solutions ranged from 8 to $14 \mathrm{~mm}$. AgNPs-H20 $(1 \mu \mathrm{g})$ caused the greatest inhibition of Candida strains. The inhibitory effect of AgNPs-H was significantly higher than that of AgNPs-C against C. albicans in the $1 \mu \mathrm{g}$ and $0.5 \mu \mathrm{g}$ variants and against $C$. parapsilosis at the $0.25 \mu \mathrm{g}$ concentration. In the case of the standard antifungal drugs used in the study, the inhibition zone ranged from 12 to $20 \mathrm{~mm}$ and from 0 to $12 \mathrm{~mm}$ in the case of $\mathrm{AmB}$ and fluconazole, respectively. AgNPs-H and AgNPs-C exhibited lower activity against C. albicans than AmB. The activity of AgNPs-H against C. albicans was comparable to that of fluconazole. However, fluconazole administered at the concentrations of $0.5 \mu \mathrm{g}$ and $0.25 \mu \mathrm{g}$ had no activity against C. parapsilosis. 


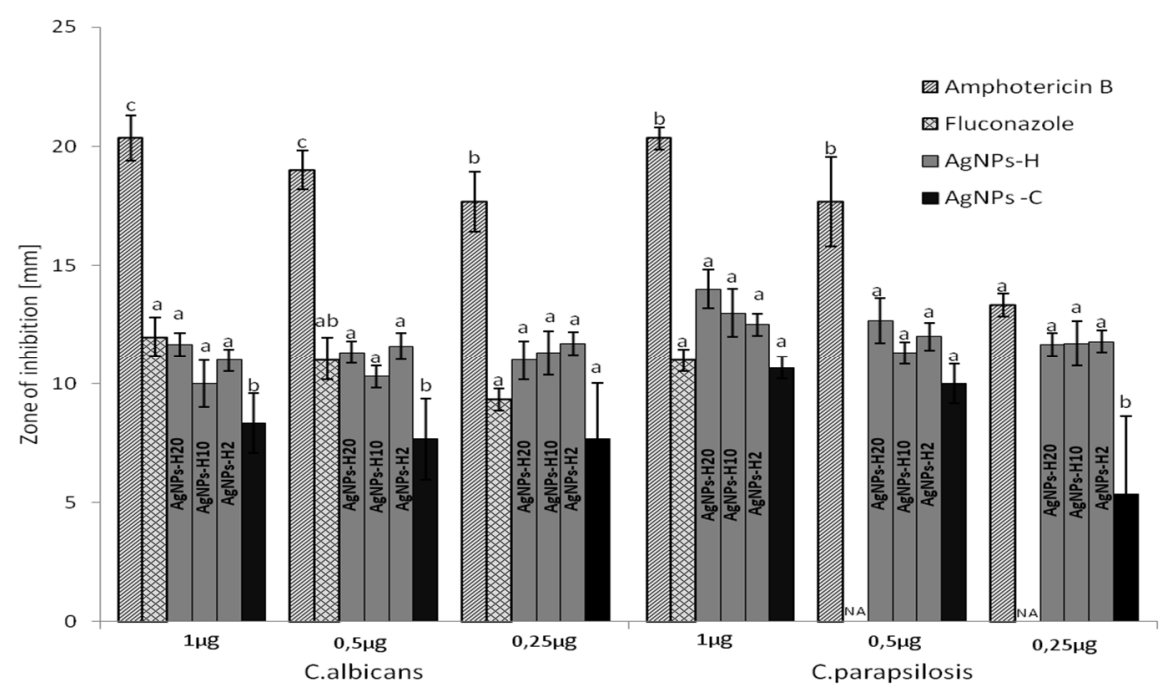

Figure 5. Graphical presentation of zone of inhibition ZOI against Candida strains. Moderate inhibition zone (6-9 mm); strong inhibition zone (10-14 mm); very strong inhibition zone (15-18 $\mathrm{mm}$ ); NA (no activity). Each result is shown as a mean value with SD of results from two cultures in three replications. The same letter means that the differences between the data compared are not statistically significant. Different letters $(a, b$, and $c)$ mean that the data compared are statistically different at $p<0.05$.

\section{Discussion}

In the first stage, the AgNPs-H synthesis was carried out at a temperature of $35^{\circ} \mathrm{C}$ (Figure 1). In these thermal conditions, the course of the synthesis was atypical in the case of some concentrations of honey. It was expected that the higher content of reducing agents in the $20 \%$ solution would enhance the reaction rate. Instead, the reaction did not take place at all in this concentration and proved to be highly inefficient in the 10\% solution. In the subsequent part of the study, the influence of temperature on AgNPs-H synthesis was analyzed with a focus on the highest concentration of honey in the solution. The analysis of the dependence of the reaction efficiency on the temperature [25] showed that the observed effect may be related to the aggregation of honey components. In the complex matrix of honey, macromolecules self-associate with colloidal particles at a critical concentration driven by the viscosity of honey. The detailed chemical composition of colloidal honey particles has not been fully identified [26]. As shown in previous studies, colloids in honey constituted from $0.1 \%$ to $1 \%$ of honey weight and proteins constituted $54 \%[27,28]$. Furthermore, it was observed that large colloidal particles of dark and medium honeys exhibited remarkable colloidal stability [23] although the dilution with water was increased from 16- to 32 -fold. The impact of temperature on nanoparticle synthesis in the $20 \%$ concentrated honey solution can be explained by the formation of aggregated structures as a result of protein-carbohydrate interaction $[29,30]$ and occurrence of polyphenol-protein complexes in honey. For example, noncovalent protein-protein interactions between glycosylated MRJP1 monomers lead to the formation of a large 350 to 420 Da heterohexamer apisin [31], whereas both noncovalent and covalent interactions between protein and polyphenols lead to the formation of protein-polyphenol complexes [32] and melanoidins [33]. It should be noted that these types of interactions leading to the formation of aggregates can significantly reduce the availability of reducing components in the honey solution during synthesis at low temperature [29]. In the case of lower concentrations, there are lower amounts of reducing substances which are, however, more readily available. As the concentration increases, associates of organic compounds and crystalline structures of compounds responsible for the reduction of silver ions may form. A temperature increase to $70{ }^{\circ} \mathrm{C}$ causes the breakage of bonds, particularly of the van der Waals type and hydrogen bonds, thereby initiating the processes of monomerization. Furthermore, increased temperature also significantly accelerates the reaction of $\mathrm{Ag}^{+}$ion reduction. 
The resonance light scattering (RLS) technique is commonly used for a variety of analytical measurements [34]. It can also be applied to study intermolecular interactions, particularly with regard to chromophoric aggregation processes between molecules [35] The absence of changes in $\mathrm{H}-2$ indicates no influence of temperature and $\mathrm{pH}$ on the level of aggregation; hence, AgNP synthesis occurs in this concentration at both $35^{\circ} \mathrm{C}$ and $70{ }^{\circ} \mathrm{C}$. The higher synthesis efficiency observed in this solution at the increased temperature (Figure 2A) is mostly due to the increased rate of the reaction rather than an altered level of aggregation of the components. Entirely different results were obtained for the H-20 solution. Compared to $\mathrm{H}-2$, the initial band was characterized by significantly greater intensity, and its maximum was shifted by approximately $10 \mathrm{~nm}$ in the long-wave direction.

The observed spectral differences indicated that aggregated forms (e.g., proteins) of various sizes were present in these solutions. As mentioned above, the technique allows for the observation of certain aggregate forms, particularly those resulting from chromophoric interactions within a certain size range. This means that, in most cases, it is impossible to observe small dimer and trimer structures or structures of very large sizes [36]. This may explain the increased intensity of the scattering signals in the $\mathrm{H}-20$ solutions after the temperature increase. Very large structures strongly aggregated at $35^{\circ} \mathrm{C}$ may not generate RLS signals. However, once the temperature is increased, the large structures fall apart and smaller structures emerge, to which the increased band intensity could be attributed. Only once the $\mathrm{pH}$ is increased to 9.5 does the actual disaggregation take place, which accounts for the decreased intensity of the RLS band. Summing up, this unexpected effect of increasing the intensity of RLS spectra with temperature may be related to disaggregation of bee pollen at higher temperatures. Pollen contains, on average, $20 \%$ protein and has the form of grains with quite varied sizes $(2.5-250 \mu \mathrm{m})$ [37]. Changes in the size of these structures with increasing temperature may have a significant effect on changing the intensity of RLS bands. The RLS band may be related to light scattering at the excitonic levels of interacting chromophores of compounds concentrated in the solution. The bathochromic shift of the RLS spectra in relation to the fluorescence emission spectra proves the independence of these bands from the autofluorescence of compounds contained in the solution. This indicates their relationship with chromophore aggregated molecular systems.

The results of the antifungal activity against $C$. albicans clearly indicated that fungal growth was inhibited already at concentrations of $2 \mu \mathrm{g} / \mathrm{mL}$ of AgNPs-C and $0.5 \mu \mathrm{g} / \mathrm{mL}$ of AgNPs-H2. These findings correlate well with results reported by other authors [38], who analyzed nanoparticles biosynthesized in other systems, although higher MIC values were obtained in some studies $(60 \mu \mathrm{g} / \mathrm{mL}-30 \mu \mathrm{g} / \mathrm{mL})$ [39,40]. The basic mechanisms of the antifungal activity of AgNPs consist of interactions with microbial membrane proteins and DNA, production of reactive oxygen species, and interactions with the cell wall or membrane, leading to disturbances in the membrane potential [41]. Interactions between the surface of fungal cell membrane and nanoparticles are a complex problem related to the properties of the cell membrane, nanoparticles, and the dispersing medium used. Functional groups present on the surface of nanoparticles (e.g., proteins) determine many essential properties of nanomaterials, e.g., solubility or surface charge, which influence the interaction of nanomaterials with the cell surface, including internalization of nanoparticles [4,42-44]. The net negative surface electrical charge of the cell membrane facilitates electrostatic attraction with the positively charged nanoparticles or with the functional groups of macromolecules present in the solution [45]. However, the surface of the cell membrane is usually nonhomogeneous in terms of the electrical charge distribution. The net electrical charge of the cell surface varies among Candida species [46]. In our study, the hydrodynamic diameter of AgNPs-H was higher than that of AgNPs-C. The literature describes a correlation between antimicrobial activity and the size of nanoparticles [47-49]. It has been shown that the activity generally increases with a decrease in nanoparticle diameter. In contrast, the authors of the study [50] demonstrated that antifungal activity does not depend on the nanoparticle size. This was confirmed by our research showing that AgNPs-C with a smaller diameter exhibited less potent antifungal activity. These results 
may be associated with the impact of the surface charge, as well as the composition and structure of the electrical double layer around AgNPs [51]. There are only limited data on the zeta potential of stabilized AgNPs analyzed for antimicrobial activity [38,52-55]. Such activity of AgNPs synthesized using maltose was investigated by Çulha et al. [56]. The zeta potential value determined by these authors was close to that obtained for AgNPs-H, while the zeta potential of AgNPs synthesized using honey from Z. spina-christi and A. gerrardii was close to zero [57]. In the present study, the values of the zeta potential of both AgNPs-C and AgNPs-H were negative. However, the absolute value of the zeta potential of AgNPs-H was lower (less negative) than that of AgNPs-C (Table 1), probably resulting in weaker repulsion from the cell membrane. This suggests that the AgNPs-H were less repelled from the membrane surface than the AgNPs-C. Additionally, the Candida species were different, considering their surface charge. It was shown that the value of zeta potential of $C$. parapsilosis was more negative than that of $C$. albicans. [46]. The presence of flavonoids contained in honey may also be an additional factor responsible for the increasing activity of AgNPs-H [12]. This effect may result from the synergistic action of nanoparticles and phenolic compounds contained in honey.

In the case of AgNPs-H10 and AgNPs-H20, no activity and even stimulated fungal growth were observed. One of the mechanisms of the lower activity of the solutions with the higher honey content may be related to the fact that honey components are a substrate for Candida growth. The honey concentrations in the case of AgNPs-H20 applied in the range of $16-8 \mu \mathrm{g} / \mathrm{mL}$ (Figure 4 ) were $3.2-1.65 \%$, and stimulation of $C$. albicans growth was observed. A similar effect was described in [21], where the authors analyzed the effect of honey concentration on its antifungal activity. The analysis of the OD curves related to fungal growth revealed a clear peak at the $2.5 \%$ and $5 \%$ concentrations. The additional carbohydrates, as in the case of the sugar control, stimulated C. albicans growth to an optimal level. Above this concentration, the inhibitory factors present in the honey partially inhibited the growth of the fungi. The analysis of the ZOI revealed no significant relationship between the activity and the concentration of honey used for the synthesis of nanoparticles. The components of the sample placed on the dish surface did not diffuse; hence, there was no stimulatory effect of the honey components on fungal growth. Additionally, evaporation leads to natural concentration of the sample. The concentration increases to a level where honey inhibits fungal growth. This is in line with other reports [58], where the addition of undiluted honey to the culture medium resulted in complete growth inhibition. The addition of $50 \%$ and $20 \%$ of honey into the fungal growth medium resulted in sparse growth and good growth, respectively. This may mean that there is a range of concentrations in which honey can serve as a nutrient and promote microbial growth. AgNPs-H were also highly active in the disc diffusion test, although their activity was lower than that of (AmB). Noteworthy, this antibiotic is a highly effective antifungal agent used as the gold standard with which newer agents are compared $[59,60]$. In comparison with fluconazole, the AgNPs-H activity was similar in the case of $\mathrm{C}$. albicans and better than the drug against $C$. parapsilosis.

\section{Conclusions}

The present study focused on the synthesis of AgNPs with the use of aqueous honey solutions in the specified concentration and temperature conditions. It was shown that the higher temperature of $70{ }^{\circ} \mathrm{C}$ was necessary to initiate the synthesis of AgNPs in the $20 \%$ solution. The lower temperature was sufficient only in the case of the $2 \%$ solution. The inhibition of AgNP synthesis in the $20 \%$ solution at $35^{\circ} \mathrm{C}$ was probably related to the process of protein aggregation, as corroborated by the results obtained with most of the analytic techniques used, particularly RLS.

The AgNPs-H were shown to have higher antifungal activity than AgNPs-C. This may be related to the different zeta potentials of the analyzed colloids. The higher activity of AgNPs-H may also be associated with the presence of flavonoids contained in honey, which have proven antimicrobial activity. The antifungal activity of AgNPs-H was dependent on 
the concentration of honey. In the microdilution studies, the higher concentrations of honey used for the synthesis of nanoparticles served as a substrate for the fungal strains. The analysis of the inhibition zones showed similar effectiveness of nanoparticles synthesized at the high and low concentrations of honey. This may imply different biomedical applications of AgNPs produced at different concentrations of honey. Further studies focused on the mechanism of action of the 'green-synthesized' AgNPs on the fungal cell membrane in honey solutions are advisable.

\section{Materials and Methods}

\subsection{Chemicals and Reagents}

Silver nitrate $\left(\mathrm{AgNO}_{3}\right)$, trisodium citrate $\left(\mathrm{C}_{6} \mathrm{H}_{5} \mathrm{O}_{7} \mathrm{Na}_{3}\right)$, sodium hydroxide $(\mathrm{NaOH})$, and hydrochloric acid $(\mathrm{HCl})$ (Sigma Aldrich, St. Louis, MO, USA) of analytical-grade purity were used as starting materials without further purification. Double-distilled water was used in all experiments.

\subsection{Citrate Reduction Method}

The synthesis of nanoparticles was carried out using a modified Lee and Meisel method [16]. Typically, $50 \mathrm{~mL}$ of a $1 \mathrm{mM} \mathrm{AgNO}$ aqueous solution was heated up to boiling temperature, and the solution was stirred vigorously during the synthesis process. While stirring, a solution of $1 \%$ sodium citrate $(5 \mathrm{~mL})$ was added. The solution was kept at the boiling point for $10 \mathrm{~min}$ until the colloids changed color. The solution was heated continuously until the color changes were apparent (pale green). At that point, heat was no longer applied, and the solution was stirred continuously until it cooled to room temperature. The size of the synthesized AgNPs was controlled by the $\mathrm{pH}$ of the solution during synthesis.

\subsection{Honey-Mediated Synthesis}

Organic fir honeydew honey was obtained from sources located in the Bieszczady Mountains (Southern Poland) and purchased directly from a beekeeper. Twenty grams of honey were dissolved in $80 \mathrm{~g}$ of deionized water, producing a $20 \%(\mathrm{H}-20)$ solution. Subsequently, two solutions, i.e., $10 \%(\mathrm{H}-10)$ and $2 \%(\mathrm{H}-2)$, were obtained by diluting the stock solution. Then, $250 \mu \mathrm{L}$ of the $\mathrm{AgNO}_{3}(100 \mathrm{mM})$ solution was added to $25 \mathrm{~mL}$ of each solution described above. To initiate the reduction of $\mathrm{Ag}^{+}$ions, the $\mathrm{pH}$ was adjusted to 9.5 using $\mathrm{NaOH}$.

\subsection{Electronic Absorption Spectroscopy}

The electronic absorption spectra were recorded using a double-beam Cary 300 Bio UV-Vis spectrophotometer (Varian, Palo Alto, CA, USA) equipped with a thermostated cuvette holder with a $6 \times 6$ multicell Peltier block. The temperature was controlled using a thermocouple probe (Cary Series II from Varian) placed directly in the sample. The FWHM (full width at half maximum) was calculated from the fits of the Voigt function to every peak with the use of OriginPro 2020 software.

\subsection{Fluorescence Spectroscopy}

Resonance light scattering (RLS) measurements were performed using a Cary Eclipse spectrofluorometer (Varian). RLS with synchronous scanning at $\lambda \mathrm{ex}=\lambda \mathrm{em}(\Delta \lambda=0)$ from 250 to $850 \mathrm{~nm}$ was recorded.

\subsection{Dynamic Light Scattering Method}

Measurements of the intensity-weighted mean hydrodynamic diameter $\left(Z_{\text {ave }}\right)$ [61], electrolytic conductivity, and electrophoretic mobility (laser doppler electrophoresis) [62] were performed by means of Zetasizer Nano ZS (Malvern Ltd., Malvern, UK) in six repetitions at $20^{\circ} \mathrm{C}$. Henry's equation was applied for calculation of the zeta potential [63]. Additionally, the differential particle size (hydrodynamic diameter) distributions and 
zeta potential distributions characterizing the synthesized particles were obtained by subtraction of the curve determined for pure honey (or citrate solution) from that describing systems containing AgNPs [24]. This was done to determine the particle diameter or zeta potential at which an increase in the percentage of scattered light intensity occurred after the AgNPs synthesis.

\subsection{Microorganism and Culture Conditions}

The reference strains of Candida albicans NCPF 3153 and Candida parapsilosis ATCC 22019 were used. The strains were stored at $-70{ }^{\circ} \mathrm{C}$ in a cryoprotective medium of VIABANK. Before the experiment, the strains were inoculated into a liquid YPD medium (peptone, $20 \mathrm{~g} / \mathrm{L}$, yeast extract, $10 \mathrm{~g} / \mathrm{L}$, glucose $20 \mathrm{~g} / \mathrm{L}$ ) and cultured for $24 \mathrm{~h}$ at $35^{\circ} \mathrm{C}$ with shaking. The fungal inoculum was adjusted to yield a concentration of $1 \times 10^{6} \mathrm{cell} / \mathrm{mL}$.

\subsection{Chemical Composition of the Honey}

Moisture and extract contents were determined using an Abbe Carl Zeiss refractometer (Germany) on the basis of the refractive index of the honey in its liquid state according to Bogdanov [64]. The $\mathrm{pH}$ and electrical conductivity were determined as described earlier [64] using a pIONneer 65 Meter (Radiometer Analytical, Villeurbanne, CEDEXFrance) with a combined pH electrode (E16M340) and a four-pole conductivity cell (CDC 30T) with a built-in temperature sensor. Free acidity was determined by potentiometric titration with $0.1 \mathrm{~N}$ sodium hydroxide solution $(\mathrm{NaOH})$ and expressed as milliequivalents of acid per kg of honey [64]. The concentration of 5-HMF (5-(hydroxymethyl-)furan-2carbaldehyde) was determined according to White [65]. The measurement was made with a Carry 300 Bio spectrophotometer (Varian Australia PTY, Ltd., Belrose, NSW, Australia) at wavelengths of 284 and $336 \mathrm{~nm}$, and the results were expressed as $\mathrm{mg} / \mathrm{kg}$. Total phenolic content was determined in a reaction with Folin-Ciocâlteu $(\mathrm{F}-\mathrm{C})$ reagent according to the procedure described by Singleton and Rossi [66], and the results were expressed as gallic acid equivalent in $\mathrm{mg}$ GAE/ $\mathrm{kg}$ of honey. Total flavonoid content was determined in a reaction with aluminum chloride according to Ardestani and Yazdanparast [67], and the results were expressed as quercetin equivalent (QE) in mg QE/100 g of sample. The chemical composition and physicochemical properties of fir honeydew are presented in Table 3.

Table 3. Characteristics of physicochemical properties and antioxidant activity of honey (means \pm standard deviations).

\begin{tabular}{|c|c|}
\hline Parameter & Fir Honeydew \\
\hline Moisture (\%) & $16.42 \pm 0.03$ \\
\hline Extract $(\%)$ & $82.08 \pm 0.03$ \\
\hline $\mathrm{pH}$ & $4.28 \pm 0.03$ \\
\hline Free acidity $\left(\mathrm{mEq} \cdot \mathrm{kg}^{-1}\right)$ & $41.2 \pm 0.28$ \\
\hline Electrical conductivity $\left(\mathrm{mS} \cdot \mathrm{cm}^{-1}\right)$ & $1.124 \pm 0.005$ \\
\hline $5-\mathrm{HMF}\left(\mathrm{mg} \cdot \mathrm{kg}^{-1}\right)$ & $0.61 \pm 0.8$ \\
\hline Total polyphenols (mg GAE/100 g) & $63.25 \pm 0.09$ \\
\hline Total flavonoids (mg QE/100 g) & $9.4 \pm 0.07$ \\
\hline
\end{tabular}

\subsection{Broth Microdilution Method}

The broth microdilution method with identification of the minimal inhibitory concentration (MIC) was employed according to the standard methodological guidelines recommended by the Clinical and Laboratory Standards Institute (CLSI), document M27A3 and M38-A2, for testing the susceptibility of yeasts. The method was modified by addition of $2 \%$ glucose to RPMI 1640 medium in order to optimize the fungal growth conditions. To determine the MIC values, an inoculum was prepared with the final density of $0.5-2.5 \times 10^{3}$ cells $/ \mathrm{mL}$ for yeast, diluted in RPMI 1640 medium, without phenol red and sodium bicarbonate, buffered to $\mathrm{pH} 7.0$ with $0.165 \mathrm{~mol} / \mathrm{L} \mathrm{3-(N-morpholino}$ )- 
propanesulfonic acid (MOPS) and supplemented with $2 \%$ of glucose. The stock solutions of AgNPs were used to obtain the final dilutions in the broth medium on 96-well microtiter plates. The control of fungal growth was performed in medium supplemented with the solvent. After inoculation, the microtiter plates were incubated for $48 \mathrm{~h}$ at a temperature of $35^{\circ} \mathrm{C}$. The optical density was determined spectrophotometrically using an EPOCH 2 microplate reader (BioTek, Winooski, VT, USA) at a wavelength of $600 \mathrm{~nm}$. The MIC value was determined by calculating the percentage of the control growth in each replication. The MIC was the lowest concentration of AgNPs capable of 50\% inhibition of fungal growth in comparison with the growth of AgNPs-untreated cells.

\subsection{Disc Diffusion Assay}

The antifungal activity was achieved using the Kirby-Bauer disc diffusion method. The disc diffusion tests were carried out to determine the size-selective bacterial sensitivity toward AgNPs, marked by their ZOI. A suspension of all Candida strains $(0.1 \mathrm{~mL}$ of $10^{6}$ cells $/ \mathrm{mL}$ ) was spread on plates with YPD agar medium (peptone, $20 \mathrm{~g} / \mathrm{L}$, yeast extract, $10 \mathrm{~g} / \mathrm{L}$, glucose $20 \mathrm{~g} / \mathrm{L}$, agar, $20 \mathrm{~g} / \mathrm{L}$ ). Sterile $6 \mathrm{~mm}$ paper discs impregnated with the solution of AgNPs ( $1 \mu \mathrm{g} / \mathrm{disc}, 0.5 \mu \mathrm{g} / \mathrm{disc}$, and $0.25 \mu \mathrm{g} / \mathrm{disc})$ were placed on the inoculated surface. The test was also performed with AmB $(1 \mu \mathrm{g} / \mathrm{disc}, 0.5 \mu \mathrm{g} / \mathrm{disc}$, and $0.25 \mu \mathrm{g} / \mathrm{disc})$ and fluconazole $(1 \mu \mathrm{g} / \mathrm{disc}, 0.5 \mu \mathrm{g} / \mathrm{disc}$, and $0.25 \mu \mathrm{g} / \mathrm{disc})$. The plates were incubated at $35^{\circ} \mathrm{C}$ for $24 \mathrm{~h}$. The results were read after $24 \mathrm{~h}$ of incubation. The diameters of the inhibition zones were measured in millimeters.

\subsection{Statistical Analysis}

The tests were carried out in triplicate, and experimental data were reported as the mean \pm standard deviation (SD). The differences in antifungal activities of all antifungal agents were compared by ANOVA in OriginPro 2020 software. A $p$-value $<0.05$ was considered statistically significant.

Author Contributions: Conceptualization, G.C.; data curation, G.C., D.B., A.M., J.C., M.K.-M. and M.F.; formal analysis, G.C., D.B., J.C. and M.F.; funding acquisition, G.C., A.M. and M.G.; investigation, G.C., D.B., A.M., J.C. and M.K.-M.; methodology, G.C., D.B. and J.C.; project administration, G.C.; resources, G.C.; software, A.M. and M.G.; supervision, G.C.; validation, G.C., A.M., M.F. and M.G.; visualization, G.C.; writing-original draft, G.C. All authors have read and agreed to the published version of the manuscript.

Funding: The authors acknowledge financial support from the National Science Center of Poland under project no. 2019/35/B/NZ7/02756. The author Grzegorz Czernel acknowledges the financial support from the University of Life Sciences in Lublin under project no. LKB/MN-1/19.

Institutional Review Board Statement: Not applicable.

Informed Consent Statement: Not applicable.

Data Availability Statement: Data is contained within the article.

Conflicts of Interest: The authors declare no conflict of interest.

\section{References}

1. Sardi, J.C.O.; Scorzoni, L.; Bernardi, T.; Fusco-Almeida, A.M.; Mendes Giannini, M.J.S. Candida species: Current epidemiology, pathogenicity, biofilm formation, natural antifungal products and new therapeutic options. J. Med. Microbiol. 2013, 62 Pt 1, 10-24. [CrossRef]

2. de Oliveira Santos, G.C.; Vasconcelos, C.C.; Lopes, A.J.O.; de Sousa Cartágenes, M.d.S.; Filho, A.K.D.B.; do Nascimento, F.R.F.; Ramos, R.M.; Pires, E.R.R.B.; de Andrade, M.S.; Rocha, F.M.G.; et al. Candida Infections and Therapeutic Strategies: Mechanisms of Action for Traditional and Alternative Agents. Front. Microbiol. 2018, 9, 1351. [CrossRef]

3. Yaqoob, A.A.; Umar, K.; Ibrahim, M.N.M. Silver nanoparticles: Various methods of synthesis, size affecting factors and their potential applications-a review. Appl. Nanosci. 2020, 10, 1369-1378. [CrossRef]

4. Wei, L.; Lu, J.; Xu, H.; Patel, A.; Chen, Z.-S.; Chen, G. Silver nanoparticles: Synthesis, properties, and therapeutic applications. Drug Discov. Today 2015, 20, 595-601. [CrossRef]

5. Chen, X.; Schluesener, H.J. Nanosilver: A nanoproduct in medical application. Toxicol. Lett. 2008, 176, 1-12. [CrossRef] 
6. Padnya, P.; Gorbachuk, V.; Stoikov, I. The Role of Calix[n]arenes and Pillar[n]arenes in the Design of Silver Nanoparticles: Self-Assembly and Application. Int. J. Mol. Sci. 2020, 21, 1425. [CrossRef]

7. Crisan, C.M.; Mocan, T.; Manolea, M.; Lasca, L.I.; Tăbăran, F.-A.; Mocan, L. Review on Silver Nanoparticles as a Novel Class of Antibacterial Solutions. Appl. Sci. 2021, 11, 1120. [CrossRef]

8. Tyavambiza, C.; Elbagory, A.M.; Madiehe, A.M.; Meyer, M.; Meyer, S. The Antimicrobial and Anti-Inflammatory Effects of Silver Nanoparticles Synthesised from Cotyledon orbiculata Aqueous Extract. Nanomaterials 2021, 11, 1343. [CrossRef] [PubMed]

9. Abdelghany, T.M.; Al-Rajhi, A.M.H.; Al Abboud, M.A.; Alawlaqi, M.M.; Ganash Magdah, A.; Helmy, E.A.M.; Mabrouk, A.S. Recent Advances in Green Synthesis of Silver Nanoparticles and Their Applications: About Future Directions. A Review. BioNanoScience 2018, 8, 5-16. [CrossRef]

10. Santos-Buelga, C.; González-Paramás, A.M. Chemical Composition of Honey. In Bee Products—Chemical and Biological Properties; Alvarez-Suarez, J.M., Ed.; Springer International Publishing: Cham, Switzerland, 2017; pp. 43-82.

11. Philip, D. Honey mediated green synthesis of silver nanoparticles. Spectrochim. Acta Part A Mol. Biomol. Spectrosc. 2010, 75, 1078-1081. [CrossRef] [PubMed]

12. Candiracci, M.; Citterio, B.; Diamantini, G.; Blasa, M.; Accorsi, A.; Piatti, E. Honey Flavonoids, Natural Antifungal Agents Against Candida Albicans. Int. J. Food Prop. 2011, 14, 799-808. [CrossRef]

13. Ghramh, H.A.; Ibrahim, E.H.; Kilany, M. Study of anticancer, antimicrobial, immunomodulatory, and silver nanoparticles production by Sidr honey from three different sources. Food Sci. Nutr. 2019, 8, 445-455. [CrossRef]

14. Ghramh, H.A.; Ibrahim, E.H.; Ahmad, Z. Antimicrobial, immunomodulatory and cytotoxic activities of green synthesized nanoparticles from Acacia honey and Calotropis procera. Saudi J. Biol. Sci. 2021, 28, 3367-3373. [CrossRef]

15. Sreelakshmi, C.; Datta, K.K.R.; Yadav, J.S.; Reddy, B.V.S. Honey Derivatized Au and Ag Nanoparticles and Evaluation of Its Antimicrobial Activity. J. Nanosci. Nanotechnol. 2011, 11, 6995-7000. [CrossRef] [PubMed]

16. Czernel, G.; Waśko, A.; Gustaw, K.; Kamiński, D.M.; Matwijczuk, A.P.; Nowicka, A.; Matwijczuk, A.S.; Oniszczuk, T.; Arczewska, M.; Karcz, D. Antimicrobial efficacy of mixtures of silver nanoparticles and polyhydric alcohols against health-promoting bacteria. Int. Agrophys. 2019, 33, 473-480. [CrossRef]

17. Wan, Y.; Guo, Z.; Jiang, X.; Fang, K.; Lu, X.; Zhang, Y.; Gu, N. Quasi-spherical silver nanoparticles: Aqueous synthesis and size control by the seed-mediated Lee-Meisel method. J. Colloid Interface Sci. 2013, 394, 263-268. [CrossRef] [PubMed]

18. Cao, Y.; Zheng, R.; Ji, X.; Liu, H.; Xie, R.; Yang, W. Syntheses and Characterization of Nearly Monodispersed, Size-Tunable Silver Nanoparticles over a Wide Size Range of 7-200 nm by Tannic Acid Reduction. Langmuir 2014, 30, 3876-3882. [CrossRef] [PubMed]

19. Durmazel, S.; Üzer, A.; Erbil, B.; Sayın, B.; Apak, R. Silver Nanoparticle Formation-Based Colorimetric Determination of Reducing Sugars in Food Extracts via Tollens' Reagent. ACS Omega 2019, 4, 7596-7604. [CrossRef] [PubMed]

20. Wang, W.; Chen, X.; Efrima, S. Silver Nanoparticles Capped by Long-Chain Unsaturated Carboxylates. J. Phys. Chem. B 1999, 103, 7238-7246. [CrossRef]

21. Wilczyńska, A.; Żak, N. The Use of Fluorescence Spectrometry to Determine the Botanical Origin of Filtered Honeys. Molecules 2020, 25, 1350. [CrossRef]

22. Ghosh, N.; Verma, Y.; Majumder, S.K.; Gupta, P.K. A Fluorescence Spectroscopic Study of Honey and Cane Sugar Syrup. Food Sci. Technol. Res. 2005, 11, 59-62. [CrossRef]

23. Brudzynski, K.; Miotto, D.; Kim, L.; Sjaarda, C.; Maldonado-Alvarez, L.; Fukś, H. Active macromolecules of honey form colloidal particles essential for honey antibacterial activity and hydrogen peroxide production. Sci. Rep. 2017, 7, 7637. [CrossRef]

24. Cieśla, J.; Chylińska, M.; Zdunek, A.; Szymańska-Chargot, M. Effect of different conditions of synthesis on properties of silver nanoparticles stabilized by nanocellulose from carrot pomace. Carbohydr. Polym. 2020, 245, 116513. [CrossRef] [PubMed]

25. Rosa, M.; Roberts, C.J.; Rodrigues, M.A. Connecting high-temperature and low-temperature protein stability and aggregation. PLoS ONE 2017, 12, e0176748. [CrossRef] [PubMed]

26. Brudzynski, K.; Sjaarda, C.P. Colloidal structure of honey and its influence on antibacterial activity. Compr. Rev. Food Sci. Food Saf. 2021, 20, 2063-2080. [CrossRef]

27. Lothrop, R.E.; Paine, H.S. Some Properties of Honey Colloids and the Removal of Colloids from Honey with Bentonite. Ind. Eng. Chem. 1931, 23, 328-332. [CrossRef]

28. Bogdanov, S.; Jurendic, T.; Sieber, R.; Gallmann, P. Honey for Nutrition and Health: A Review. J. Am. Coll. Nutr. 2008, 27, 677-689. [CrossRef]

29. Soltanizadeh, N.; Mirmoghtadaie, L.; Nejati, F.; Najafabadi, L.I.; Heshmati, M.K.; Jafari, M. Solid-State Protein-Carbohydrate Interactions and Their Application in the Food Industry. Compr. Rev. Food Sci. Food Saf. 2014, 13, 860-870. [CrossRef]

30. Voynov, V.; Chennamsetty, N.; Kayser, V.; Helk, B.; Forrer, K.; Zhang, H.; Fritsch, C.; Heine, H.; Trout, B.L. Dynamic Fluctuations of Protein-Carbohydrate Interactions Promote Protein Aggregation. PLoS ONE 2009, 4, e8425. [CrossRef]

31. Kimura, M.; Kimura, Y.; Tsumura, K.; Okihara, K.; Sugimoto, H.; Yamada, H.; Yonekura, M. 350-kDa Royal Jelly Glycoprotein (Apisin), Which Stimulates Proliferation of Human Monocytes, Bears the $\beta 1-3 G$ alactosylated N-Glycan: Analysis of the NGlycosylation Site. Biosci. Biotechnol. Biochem. 2003, 67, 2055-2058. [CrossRef]

32. Brudzynski, K.; Sjaarda, C.; Maldonado-Alvarez, L. A new look on protein-polyphenol complexation during honey storage: Is this a random or organized event with the help of dirigent-like proteins? PLoS ONE 2013, 8, e72897. [CrossRef] 
33. Turkmen, N.; Sari, F.; Poyrazoglu, E.S.; Velioglu, Y.S. Effects of prolonged heating on antioxidant activity and colour of honey. Food Chem. 2006, 95, 653-657. [CrossRef]

34. Liu, S.P.; Liu, Z.F.; Luo, H.Q. Resonance Rayleigh scattering method for the determination of trace amounts of cadmium with iodide-rhodamine dye systems. Anal. Chim. Acta 2000, 407, 255-260. [CrossRef]

35. Pasternack, R.; Collings, P. Resonance light scattering: A new technique for studying chromophore aggregation. Science 1995, 269, 935-939. [CrossRef]

36. Collings, P.J.; Gibbs, E.J.; Starr, T.E.; Vafek, O.; Yee, C.; Pomerance, L.A.; Pasternack, R.F. Resonance Light Scattering and Its Application in Determining the Size, Shape, and Aggregation Number for Supramolecular Assemblies of Chromophores. J. Phys. Chem. B 1999, 103, 8474-8481. [CrossRef]

37. Komosinska-Vassev, K.; Olczyk, P.; Kaźmierczak, J.; Mencner, L.; Olczyk, K. Bee Pollen: Chemical Composition and Therapeutic Application. Evid. Based Complement. Altern. Med. 2015, 2015, 297425. [CrossRef]

38. Khatoon, U.T.; Nageswara Rao, G.V.S.; Mohan, K.M.; Ramanaviciene, A.; Ramanavicius, A. Antibacterial and antifungal activity of silver nanospheres synthesized by tri-sodium citrate assisted chemical approach. Vacuum 2017, 146, 259-265. [CrossRef]

39. Khatoon, N.; Mishra, A.; Alam, H.; Manzoor, N.; Sardar, M. Biosynthesis, Characterization, and Antifungal Activity of the Silver Nanoparticles Against Pathogenic Candida species. BioNanoScience 2015, 5, 65-74. [CrossRef]

40. Rahisuddin; Al-Thabaiti, S.A.; Khan, Z.; Manzoor, N. Biosynthesis of silver nanoparticles and its antibacterial and antifungal activities towards Gram-positive, Gram-negative bacterial strains and different species of Candida fungus. Bioprocess Biosyst. Eng. 2015, 38, 1773-1781. [CrossRef]

41. Kim, K.-J.; Sung, W.S.; Suh, B.K.; Moon, S.-K.; Choi, J.-S.; Kim, J.G.; Lee, D.G. Antifungal activity and mode of action of silver nano-particles on Candida albicans. BioMetals 2009, 22, 235-242. [CrossRef]

42. Powers, C.M.; Badireddy, A.R.; Ryde, I.T.; Seidler, F.J.; Slotkin, T.A. Silver Nanoparticles Compromise Neurodevelopment in PC12 Cells: Critical Contributions of Silver Ion, Particle Size, Coating, and Composition. Environ. Health Perspect. 2011, 119, 37-44. [CrossRef] [PubMed]

43. Loza, K.; Diendorf, J.; Sengstock, C.; Ruiz-Gonzalez, L.; Gonzalez-Calbet, J.M.; Vallet-Regi, M.; Köller, M.; Epple, M. The dissolution and biological effects of silver nanoparticles in biological media. J. Mater. Chem. B 2014, 2, 1634-1643. [CrossRef] [PubMed]

44. Liu, H.-L.; Dai, S.A.; Fu, K.-Y.; Hsu, S.-H. Antibacterial properties of silver nanoparticles in three different sizes and their nanocomposites with a new waterborne polyurethane. Int. J. Nanomed. 2010, 5, 1017-1028.

45. Henriques, M.; Azeredo, J.; Oliveira, R. Adhesion of Candida albicans and Candida dubliniensis to acrylic and hydroxyapatite. Colloids Surf. B Biointerfaces 2004, 33, 235-241. [CrossRef]

46. Palmeira-de-Oliveira, A.; Passarinha, L.A.; Gaspar, C.; Palmeira-de-Oliveira, R.; Sarmento, B.; Martinez-de-Oliveira, J.; Pina-Vaz, C.; Rodrigues, A.G.; Queiroz, J.A. The relationship between Candida species charge density and chitosan activity evaluated by ion-exchange chromatography. J. Chromatogr. B 2011, 879, 3749-3751. [CrossRef]

47. Ivask, A.; Kurvet, I.; Kasemets, K.; Blinova, I.; Aruoja, V.; Suppi, S.; Vija, H.; Käkinen, A.; Titma, T.; Heinlaan, M.; et al. SizeDependent Toxicity of Silver Nanoparticles to Bacteria, Yeast, Algae, Crustaceans and Mammalian Cells In Vitro. PLoS ONE 2014, 9, e102108. [CrossRef]

48. Lok, C.-N.; Ho, C.-M.; Chen, R.; He, Q.-Y.; Yu, W.-Y.; Sun, H.; Tam, P.K.-H.; Chiu, J.-F.; Che, C.-M. Silver nanoparticles: Partial oxidation and antibacterial activities. JBIC J. Biol. Inorg. Chem. 2007, 12, 527-534. [CrossRef]

49. Panáček, A.; Kvítek, L.; Prucek, R.; Kolář, M.; Večeřová, R.; Pizúrová, N.; Sharma, V.K.; Nevěčná, T.J.; Zbořil, R. Silver Colloid Nanoparticles: Synthesis, Characterization, and Their Antibacterial Activity. J. Phys. Chem. B 2006, 110, 16248-16253. [CrossRef] [PubMed]

50. Monteiro, D.R.; Silva, S.; Negri, M.; Gorup, L.F.; de Camargo, E.R.; Oliveira, R.; Barbosa, D.B.; Henriques, M. Silver nanoparticles: Influence of stabilizing agent and diameter on antifungal activity against Candida albicans and Candida glabrata biofilms. Lett. Appl. Microbiol. 2012, 54, 383-391. [CrossRef] [PubMed]

51. Haider, M.J.; Mehdi, M.S. Study of morphology and Zeta Potential analyzer for the Silver Nanoparticles. Int. J. Sci. Eng. Res. 2014, 7, 381-385.

52. Stoimenov, P.K.; Klinger, R.L.; Marchin, G.L.; Klabunde, K.J. Metal Oxide Nanoparticles as Bactericidal Agents. Langmuir 2002, 18, 6679-6686. [CrossRef]

53. Sondi, I.; Goia, D.V.; Matijević, E. Preparation of highly concentrated stable dispersions of uniform silver nanoparticles. J. Colloid Interface Sci. 2003, 260, 75-81. [CrossRef]

54. Long, D.; Wu, G.; Chen, S. Preparation of oligochitosan stabilized silver nanoparticles by gamma irradiation. Radiat. Phys. Chem. 2007, 76, 1126-1131. [CrossRef]

55. Hamouda, T.; Baker Jr, J.R. Antimicrobial mechanism of action of surfactant lipid preparations in enteric Gram-negative bacilli. J. Appl. Microbiol. 2000, 89, 397-403. [CrossRef] [PubMed]

56. Çulha, M.; Kalay, Ş.; Sevim, E.; Pinarbaş, M.; Baş, Y.; Akpinar, R.; Karaoğlu, Ş.A. Biocidal properties of maltose reduced silver nanoparticles against American foulbrood diseases pathogens. BioMetals 2017, 30, 893-902. [CrossRef] [PubMed]

57. Al-Brahim, J.S.; Mohammed, A.E. Antioxidant, cytotoxic and antibacterial potentials of biosynthesized silver nanoparticles using bee's honey from two different floral sources in Saudi Arabia. Saudi J. Biol. Sci. 2020, 27, 363-373. [CrossRef]

58. Efem, S.E.E.; Iwara, C.I. The antimicrobial spectrum of honey and its clinical significance. Infection 1992, 20, 227-229. [CrossRef] 
59. Segal, B.H.; Walsh, T.J. Amphotericin B Is Still the Drug of Choice for Invasive Aspergillosis. Am. J. Respir. Crit. Care Med. 2006, 174, 102. [CrossRef]

60. Klimek, K.; Strubińska, J.; Czernel, G.; Ginalska, G.; Gagoś, M. In vitro evaluation of antifungal and cytotoxic activities as also the therapeutic safety of the oxidized form of amphotericin B. Chem. Biol. Interact. 2016, 256, 47-54. [CrossRef]

61. ISO STANDARD. Particle Size Analysis-Dynamic Light Scattering (DLS). Int. Organ. Stand. 2017. Available online: https: //www.iso.org/obp/ui/\#!iso:std:40942:en.

62. Mayinger, F.; Oliver, F. Optical Measurements: Techniques and Applications, 2nd edn. Meas. Sci. Technol. $2002,13,229$.

63. Delgado, A.V.; González-Caballero, F.; Hunter, R.J.; Koopal, L.K.; Lyklema, J. Measurement and interpretation of electrokinetic phenomena. J. Colloid Interface Sci. 2007, 309, 194-224. [CrossRef]

64. Bogdanov, S. Harmonised methods of the International Honey Commission. Int. Honey Comm. (IHC) Swiss Bee Res. Cent. FAM Liebefeld 2002, 1-62. Available online: https:/ /ihc-platform.net/ihcmethods2009.pdf.

65. White, J.W., Jr. Spectrophotometric method for hydroxymethylfurfural in honey. J. Assoc. Off. Anal. Chem. 1979, 62, 509-514. [CrossRef] [PubMed]

66. Singleton, V.L.; Rossi, J.A. Colorimetry of Total Phenolics with Phosphomolybdic-Phosphotungstic Acid Reagents. Am. J. Enol. Vitic. 1965, 16, 144-158.

67. Ardestani, A.; Yazdanparast, R. Antioxidant and free radical scavenging potential of Achillea santolina extracts. Food Chem. 2007, 104, 21-29. [CrossRef] 